\title{
Reinforcement of fiberboard containing lingo-cellulose nanofiber made from wood fibers
}

\author{
Yoichi Kojima $^{1}$ (D) Ayaka Kawabata $^{1} \cdot$ Hikaru Kobori $^{1} \cdot$ Shigehiko Suzuki $^{1} \cdot$

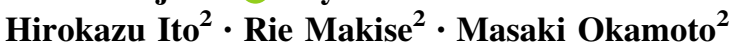

Received: 7 March 2016/ Accepted: 24 August 2016/Published online: 8 September 2016

(C) The Japan Wood Research Society 2016

\begin{abstract}
Wood-based materials are fabricated with adhesives composed of various materials derived from fossil fuels. It is difficult to identify replacements for these chemical adhesives. This study explored nanofiber technologies as an alternative to these adhesives. In this study, we focused on reinforcement effects of lingo-cellulose nanofiber (LCNF) on fiberboards made from softwood and hardwood fiber. We discuss the density effects of reinforcement with LCNF because the density of mediumdensity fiberboard (MDF), which is widely used for construction, is standardized at about $0.60-0.80 \mathrm{~g} / \mathrm{cm}^{3}$. Fiberboards were manufactured with three densities $(0.60$, 0.75 , and $1.00 \mathrm{~g} / \mathrm{cm}^{3}$ ). For softwood fiberboards, the bending properties for LCNF-mixed boards were higher than those for the control fiberboards at all densities. In this paper, control fiberboard means fiberboard with fiber only. For hardwood fiberboards, the bending properties for LCNF-mixed fiberboard for $1.00 \mathrm{~g} / \mathrm{cm}^{3}$-density board were higher than those for the control fiberboard. For internal bond strength (IB), the IB for LCNF-mixed fiberboard was higher than that for the control fiberboard. The thickness swelling (TS) and weight change (WC) with water absorption for fiberboards containing LCNF were lower than those for control fiberboards. As a conclusion, physical and mechanical properties of the resulting fiberboards were significantly improved with the addition of LCNF, especially for softwood fiberboards, due to close binding between LCNF and wood fibers.
\end{abstract}

Yoichi Kojima

aykojim@ipc.shizuoka.ac.jp

1 Faculty of Agriculture, Shizuoka University, Shizuoka, Japan

2 Toclas Corporation, Shizuoka, Japan
Keywords Wood-based materials · Fiberboard · Cellulose nanofiber $\cdot$ Ligno-cellulose nanofiber $\cdot$ Wet pulverize

\section{Introduction}

Wood-based materials are used extensively in residential construction, particularly in Japan. These materials could be made from virgin wood, recycled wood, unused wood species, or thinning wood. Many of the materials are fabricated with various adhesives. Most currently available wood adhesives, such as formaldehyde-based resins, vinyl acetate resins, and isocyanate-based resins, are composed of various materials derived from fossil fuels. Synthetic adhesives are usually nonbiodegradable constituents, and they might cause health and environmental problems. Moreover, the cost of wood-based materials might increase due to extensive use of these adhesives.

The demand for wood-based materials for use in constructions is expected to increase. Identifying replacements for these chemical adhesives poses major challenges. The global focus on sustainability demands the development of novel, natural adhesives that do not depend on fossil fuels or synthetic chemicals. Some projects have focused on developing natural, material-based wood adhesives using bio-resources. For example, some natural adhesives are composed of citric acid [1-4] or lactic acid [5, 6], but these have not been put to practical use.

In this study, we explored options involving nanofiber technology. Nanotechnology has been developing rapidly in many fields. In general, the term nanofiber refers to a nanosized fiber and is defined as a fibrous material with a diameter of about $1-100 \mathrm{~nm}$ and a length more than 100 times the diameter. A fiber that has a surface and inner structure controlled at the nanoscale is called a 
nanostructured fiber [7]. This is true even for fibers that have diameters exceeding $100 \mathrm{~nm}$.

There are many types of nanofibers. Cellulose nanofiber (CNF), particularly, has received attention in numerous fields worldwide. Over a trillion tons of CNF exist worldwide. CNF is known to have better physical and mechanical properties than most other fibers [8]. Developing new materials that incorporate $\mathrm{CNF}$ is a high priority [9-13]. Moreover, lingo-cellulose nanofiber (LCNF), which is pulverized from wood, is also expected to be applicable in many fields. However, the use of CNF technology in wood-based materials has not been reported.

In a previous study, we investigated the effects of adding CNF to wood flour [14]. The resulting properties of the $\mathrm{CNF} /$ wood flour boards were evaluated, with a focus on the binding effects of CNF. We observed that wet ball milling of commercial cellulose powder led to the formation of nanostructured fibers with nanosized surface fibrils. Moreover, the physical and mechanical properties of the wood flour boards were significantly enhanced by the addition of CNF due to three-dimensional binding between $\mathrm{CNF}$ and wood flour.

In other studies, LCNF was made from wood flour using a disk mill [15] and a ball mill [16]. In this context, CNF refers to nanofibers made from cellulose alone. In terms of reinforcement of wood flour, CNF is better than LCNF. However, in terms of productivity, LCNF is better than $\mathrm{CNF}$ because the latter requires much processing, including delignification. Thus, we employed LCNF. The fabrication of LCNF by disk milling and ball milling is simple and effective, and its incorporation into wood flour board significantly enhances the physical and mechanical properties of the board.

In the above reports, CNF and LCNF effects on wood flour board are discussed. Wood flour board is the simplest material among wood-based materials, but wood flour boards are not of practical use. Therefore, to develop our research on binding effects of CNF and LCNF on woodbased materials, we thought that a practical application to wood-based material used in residential construction was actually very important. For this reason, we focused on fiberboards.

Fiberboards are fibrous panels which made up of lignocellulosic materials joined with a synthetic binder. Fiberboards are classified based on density as high-density fiberboard (hardboard), medium-density fiberboard (MDF), and low-density fiberboard (insulation board). In particular, MDF is an important fiberboard used for residential construction and furniture worldwide. Urea-formaldehyde (UF) and phenol-formaldehyde (PF) are common resins that are used in fiberboard manufacturing because they are less expensive compared with other adhesives. However, formaldehyde emission is one of the most important disadvantages of these resins, as this could potentially cause health and pollution problems. Instead, binderless boards are wood-based composites consisting of particles of lignocellulosic material bonded without additional resin.

Recently, there has been a growing request for binderless boards. To meet the market demand and respect the environment, several studies have been performed to convert fiberboards into binder-free fiberboards using methods such as thermotreatments [17-19], the addition of soybean protein [20], pretreating fibers with white-rot fungus [18], and the addition of lignin [21,22]. Results from studies on the relationship between fiber shape and mechanical properties for medium-density fiberboard (MDF) have been reported [23-25], but there has been no mention of nanoorder fiber.

In this study, we focused on the reinforcement effects of LCNF on fiberboards made from softwood and hardwood fiber. Moreover, we discuss the density effect of reinforcement with LCNF.

\section{Materials and methods}

\section{Materials}

Softwood and hardwood fiber for MDF raw materials were used both as a base material for fiberboards and as a material for LCNF. The average fiber lengths were $2.27 \mathrm{~mm}$ (softwood) and $0.87 \mathrm{~mm}$ (hardwood).

\section{Pulverization of fiber to make LCNF}

Fibers (13.5 g, air-dry weight) were mixed with distilled water $(200 \mathrm{~g})$ and pulverized using a ball mill (Pulverizette 5; Fritsch Japan Co., Ltd., Japan). In this study, the time and rotational rate of the ball mill were fixed at $4 \mathrm{~h}$ and $200 \mathrm{rpm}$, respectively. Two LCNF slurries made from softwood and hardwood fibers were prepared and tested. Two slurries made from both unpulverized fibers served as the control. LCNF size after pulverization was measured with a laser diffraction particle size distribution analyzer (Partica LA-950; Horiba, Ltd., Kyoto, Japan).

To prevent flocculation, the LCNF slurry was replaced with alcohol. Samples were then freeze dried, and LCNF powder was produced. The surface morphology of the LCNF and unpulverized fiber were observed with a scanning electron microscope (SEM) (JSM-6510LV2; JEOL, Ltd., Japan).

\section{Fabrication of fiberboard with LCNF}

Fiberboards were made from a mixture of fibers and the LCNF slurry. Hardwood fiberboard was made from a 
mixture of hardwood fibers and the LCNF pulverized hardwood fiber. Softwood fiberboard was made from a mixture of softwood fiber and the LCNF pulverized softwood fiber. We observed the effects of LCNF on the physical and mechanical properties of fiberboards. A single composition (80 wt \% fiber +20 wt \% LCNF) was examined. Fiber (54 g dry weight) was mixed with an LCNF slurry (LCNF $13.5 \mathrm{~g}+$ distilled water $200 \mathrm{~g}$ ) in a polyethylene bag. The moisture content of the mixture was over $300 \%$.

If hot pressing occurred without desiccation, it was difficult to safely make fiberboard. When the mat moisture content was over $300 \%$, it was impossible to produce uniform boards because excessive steam pressure would accumulate, and moisture inside the mat would not completely evaporate during hot pressing, causing the mat to burst. Therefore, the mixture was compounded and dried with a compounding machine with vacuum drying function (Trimix, Inoue Mfg., Inc, Japan) to less than $30 \%$ moisture content. Compounding and drying were performed at $40 \mathrm{rpm}$ and $80{ }^{\circ} \mathrm{C}$ for $15 \mathrm{~min}$. The compounding machine was applied to mix the LCNF and wood fiber homogeneously and extract water from each compound.

As a next step, a hand-formed mat $(15 \times 15 \mathrm{~cm})$ was made using a metal frame. Wire screens (100 meshes) were placed on the upper and lower surfaces of the mat to accelerate water transfer during hot pressing. The mats were pressed for $10 \mathrm{~min}$ at $120^{\circ} \mathrm{C}$ and $0.85 \mathrm{MPa}$ using a hot press (Tabletop Test Press SA-302; Tester Sangyo Co., Ltd., Japan). In this study, to discuss the reinforcement effect of LCNF on board densities, three different board densities $\left(0.60,0.75\right.$, and $\left.1.00 \mathrm{~g} / \mathrm{cm}^{3}\right)$ were selected. Board densities were controlled by board thickness. Fiberboards $(15 \times 15 \times 0.5 \mathrm{~cm})$ were manufactured with a target density of $0.60 \mathrm{~g} / \mathrm{cm}^{3}$. For target densities of 0.75 and $1.00 \mathrm{~g} / \mathrm{cm}^{3}$, board thickness was set at 0.4 and $0.3 \mathrm{~cm}$, respectively.

For all experiments, two fiberboards were produced at each density. All boards were conditioned at $20{ }^{\circ} \mathrm{C}$ and $65 \%$ relative humidity for at least 2 weeks before testing. No adhesives were used. The boards for the control were also produced using untreated fiber.

\section{Physical testing}

After conditioning, four $12 \times 2.5 \mathrm{~cm}$ pieces were cut from each board for use in a three-point bending test with a universal testing machine. The following conditions were imposed: span of $10 \mathrm{~cm}$, loading speed of $3 \mathrm{~mm} / \mathrm{min}$. The modulus of rupture (MOR) and modulus of elasticity (MOE) was calculated.

After the bending test, two pieces $(2.5 \times 2.5 \mathrm{~cm})$ were cut from edge parts of the bending test specimen for internal bond strength (IB) and water adsorption tests. The IB test was performed under a loading speed of $3 \mathrm{~mm} / \mathrm{min}$. Water adsorption was determined by measuring the change in weight and thickness of the pieces before and after soaking in water at $20{ }^{\circ} \mathrm{C}$ for $24 \mathrm{~h}$. Eight samples were used at each test.

\section{Results and discussion}

\section{Evaluation of LCNF structure}

The sizes of the control (unpulverized fibers) for softwood and hardwood fiber were 2.27 and $0.87 \mathrm{~mm}$, respectively. After ball milling, the softwood and hardwood fiber sizes were 26.3 and $22.9 \mu \mathrm{m}$, respectively. Although the softwood fiber was 2.5 times longer than the hardwood fiber for the control, the sizes of both LCNF samples were almost identical after pulverizing at $200 \mathrm{rpm}$ for $4 \mathrm{~h}$. Figure 1 shows the size distributions of the LCNFs. The size distributions for both LCNFs were almost identical. This means that both types of fibers were sufficiently pulverized, regardless of the size before pulverizing, demonstrating that it is possible to control the size uniformity of LCNF by adjusting the settings of the ball mill. The peaks for both fibers are shown in two parts. Smaller peaks $(0.1-1 \mu \mathrm{m})$ were obtained from the small fibril formed by wet ball milling peeled from the surface of wood fiber.

The morphology of LCNF was studied with scanning electron microscope (SEM) photographs. Figures 2 and 3 show SEM photographs of the softwood and hardwood fibers before and after ball milling $(200 \mathrm{rpm} / 4 \mathrm{~h})$. The surfaces of the untreated fiber were very smooth, whereas

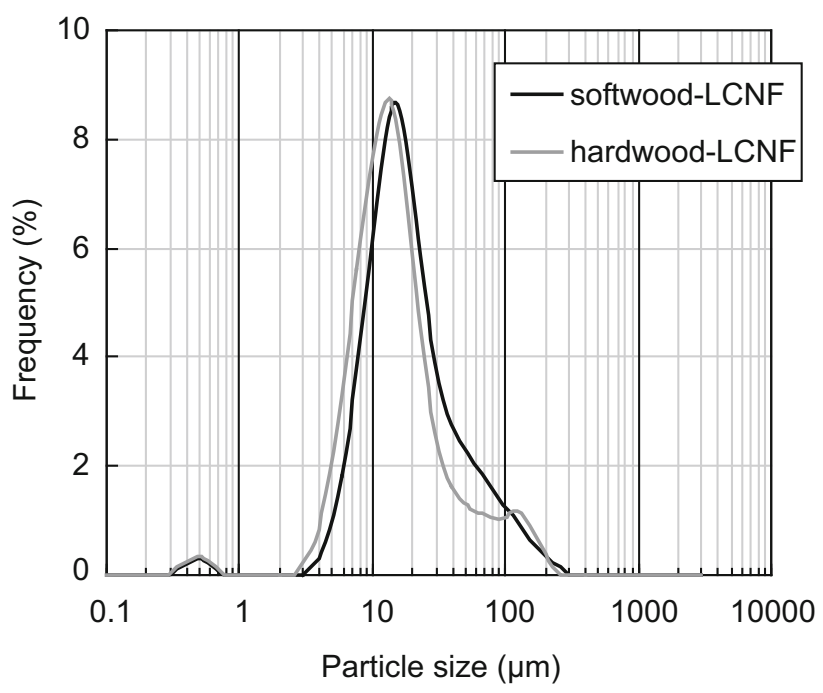

Fig. 1 Size distributions shown for softwood and hardwood fiber and LCNF 

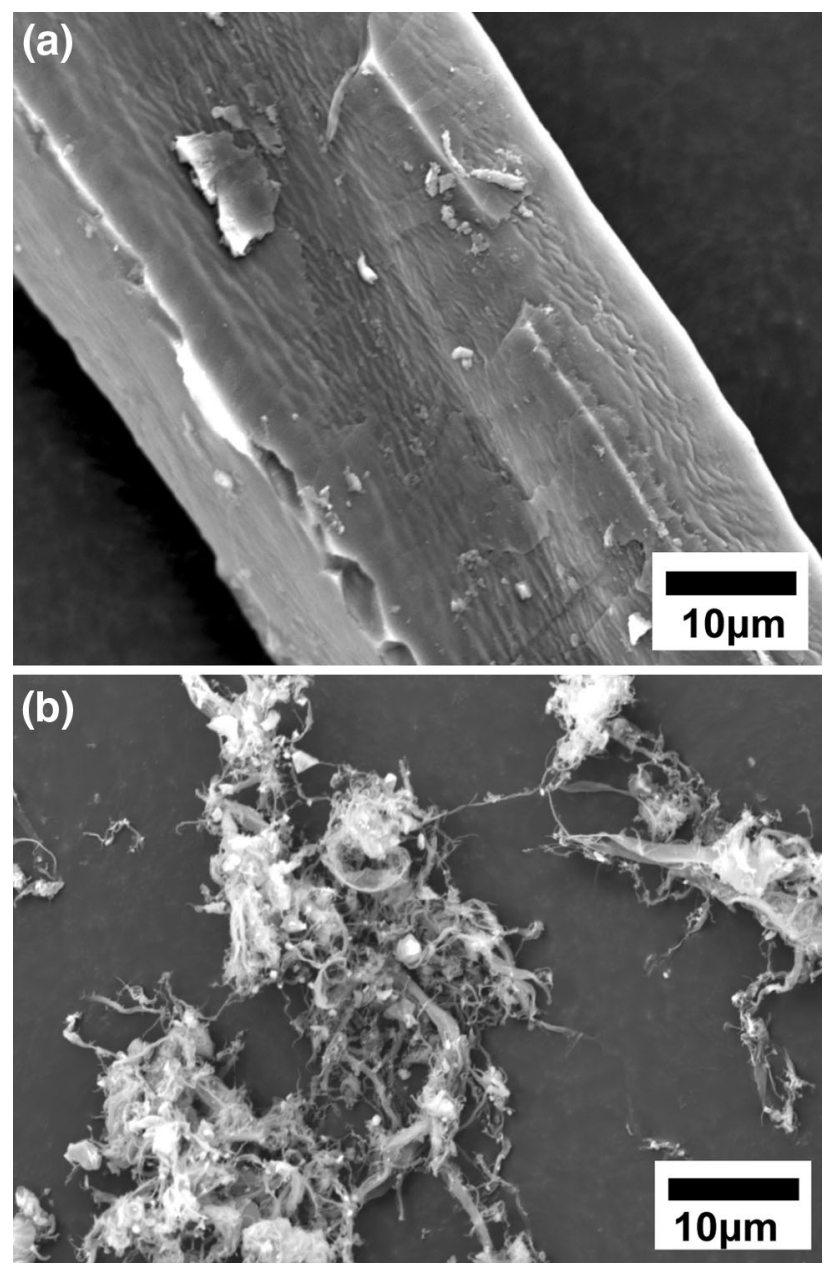

Fig. 2 SEM micrographs of the surface morphology of a untreated softwood fiber and b LCNF (200 rpm/4 h) made from softwood fiber

rougher surfaces were observed for the ball-milled fibers. Nanostructured fibers with nanoscale surface fibrils were formed on the surface of the fiber after ball milling. LCNFs made from both softwood and hardwood fiber showed the same surface structure. We have confirmed that the sizes of CNF and LCNF nanofibrils made by ball milling are the same $[14,16]$.

\section{Binding effect of LCNF in fiberboard}

A compounding machine was used in the mixing process. LCNF and wood fiber were mixed simultaneously during the drying process. Figure 4 shows the manufactured boards in this study. A compounding machine was applied to mix the LCNF and wood fiber homogeneously and extract water from each compound. As shown in this figure, the use of a compounding machine made it possible to produce fiberboards of uniform quality. The marks from wire screen were not recognized, and no surface sanding was conducted.
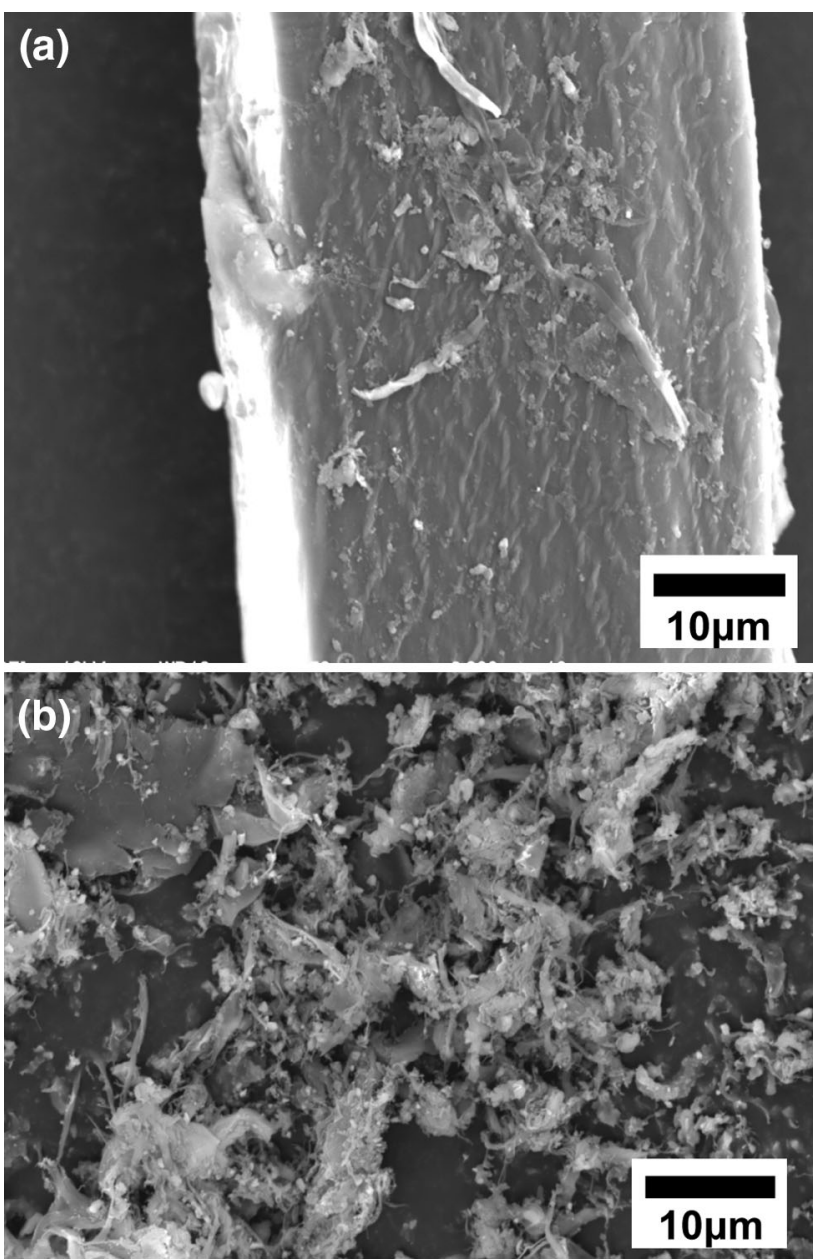

Fig. 3 SEM micrographs of the surface morphology of a untreated hardwood fiber and b LCNF $(200 \mathrm{rpm} / 4 \mathrm{~h}$ ) made from hardwood fiber

Table 1 shows the measured board densities. All fiberboards with LCNF had somewhat higher density than the target (Table 1). Moreover, some fiberboards without LCNF had a lower density than the target. This is the reason that the thickness of fiberboard without LCNF was recovered during conditioning, so the board density became lower than the targeted value. In our previous reports, the same phenomena were observed for the CNF/wood and LCNF/wood flourmixed boards $[14,16]$. According to the JIS standard (JIS A 5905) [26], fiberboards are classified based on density as hard fiberboards (hardboard, density $\geq 0.80 \mathrm{~g} / \mathrm{cm}^{3}$ ), MDF (density $0.35-0.80 \mathrm{~g} / \mathrm{cm}^{3}$ ), and insulation fiberboards (insulation board, density $\leq 0.35 \mathrm{~g} / \mathrm{cm}^{3}$ ). The densities measured in this study were MDF and Hardboard.

Because there was a difference between the control and LCNF-mixed board densities, the discussion about comparison of some mechanical properties between control and LCNF-mixed fiberboard board was conducted as specific mechanical properties (Table 1). 
Fig. 4 Manufactured board a softwood fiberboard with LCNF, b hardwood fiberboard with LCNF

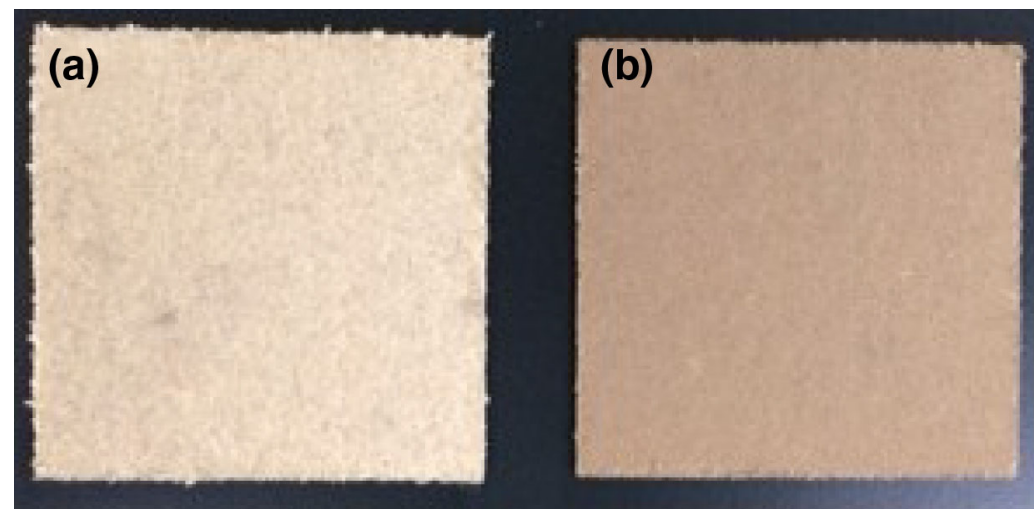

Table 1 Fiberboard densities

\begin{tabular}{llll}
\hline Target density $\left(\mathrm{g} / \mathrm{cm}^{3}\right)$ & & \multicolumn{2}{l}{ Measured density $\left(\mathrm{g} / \mathrm{cm}^{3}\right)$} \\
\cline { 3 - 4 } & & Control & LCNF mixed \\
\hline Softwood fiber & 0.60 & 0.60 & 0.65 \\
& 0.75 & 0.74 & 0.82 \\
Hardwood fiber & 1.00 & 0.95 & 1.02 \\
& 0.60 & 0.62 & 0.68 \\
& 0.75 & 0.75 & 0.83 \\
& 1.00 & 0.93 & 1.05 \\
\hline
\end{tabular}

LCNF ligno-cellulose nanofiber

Figures 5 and 6 show the bending properties [specific modulus of rupture $(\mathrm{MOR} / \rho)$ and specific modulus of elasticity $(\mathrm{MOE} / \rho)]$ of fiberboards made from softwood and hardwood fiber containing LCNF. Bending properties tended to increase with increasing board density for both control fiberboards and LCNF-mixed fiberboard. For softwood fiberboards, the bending properties for LCNF-mixed fiberboards were higher than those for the control fiberboard at all densities. On the other hand, for hardwood fiberboards, the bending properties for LCNFmixed fiberboard for $1.00 \mathrm{~g} / \mathrm{cm}^{3}$-density board were higher than those for the control fiberboard. In general, the quality of composite properties mixed with smaller size particles was not improved [27]. Nevertheless, in this study, the properties of fiberboards made with LCNF were much improved compared to wood fiber only. As a result, the nanosized fibril effectively trapped wood fibers. In our previous studies [14-16], we confirmed the reinforcement effect of LCNF on wood flour board and high board density $\left(1.00 \mathrm{~g} / \mathrm{cm}^{3}\right)$. In this report, we could confirm the application of LCNF to fiberboard at three (a)

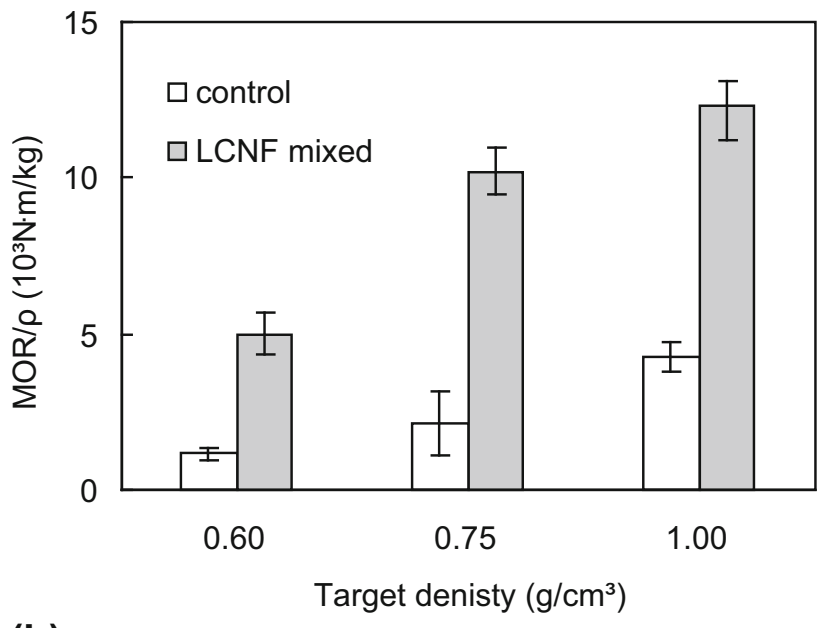

(b)

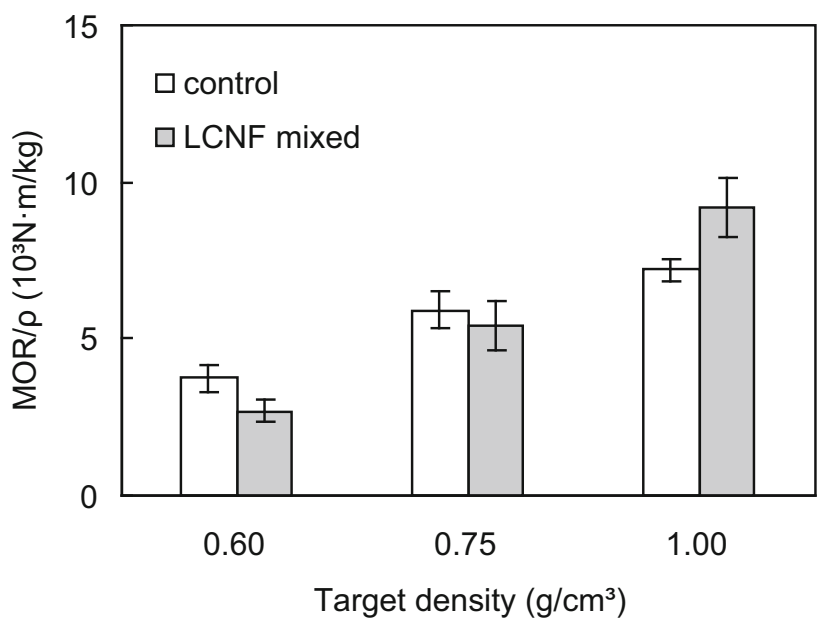

Fig. 5 Specific modulus of rupture $(\mathrm{MOR} / \rho)$ of fiberboards containing LCNF a softwood fiber, b hardwood fiber. Vertical bars indicate standard deviations 

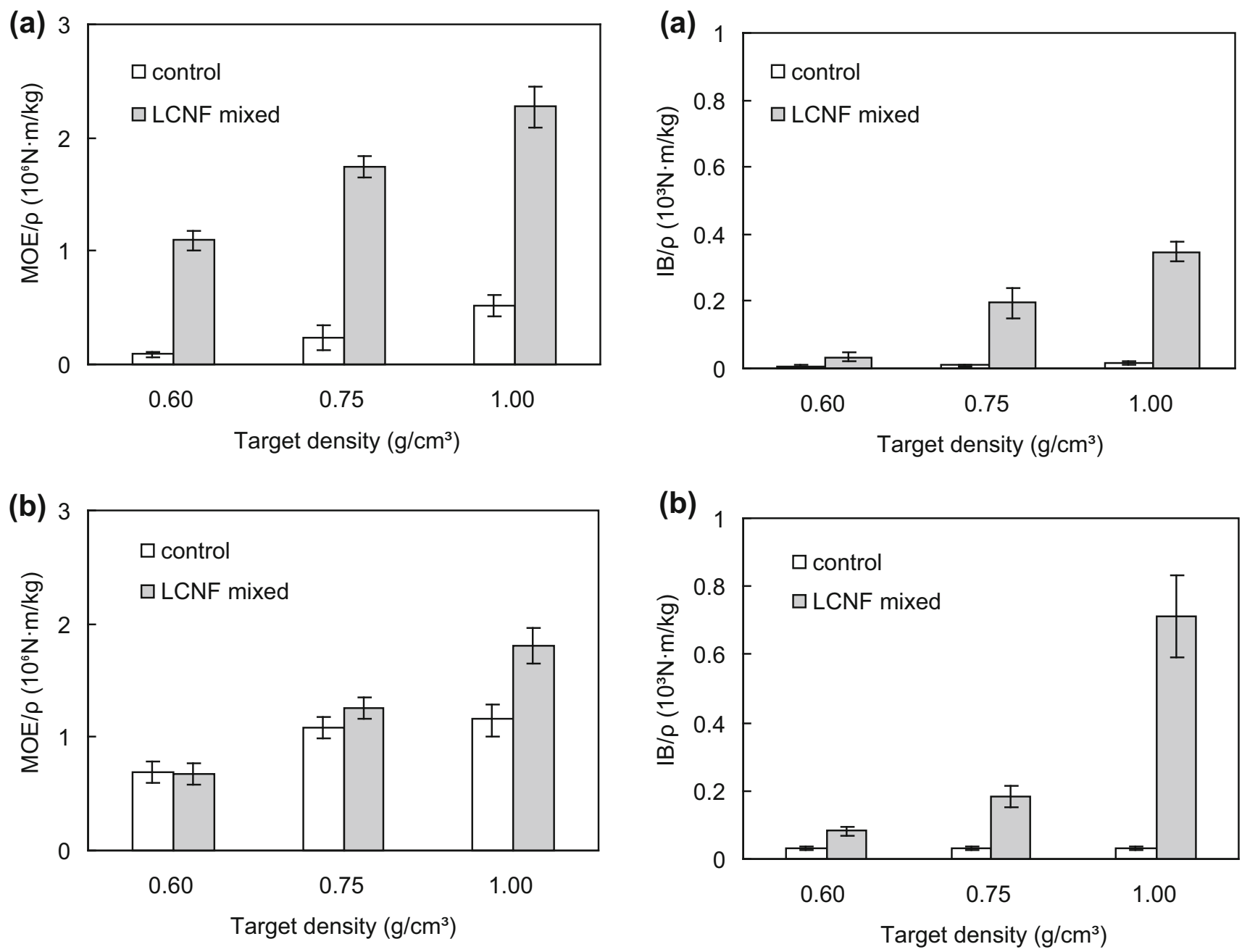

Fig. 6 Specific modulus of elasticity $(\mathrm{MOE} / \rho)$ of fiberboards containing LCNF a softwood fiber, b hardwood fiber. Vertical bars indicate standard deviations

different board densities. The mechanism of bond performance development is thought to be due to the mechanical entanglement between LCNF and fiber associated with water evaporation during hot pressing. Because the other possibilities were supposed, they should be discussed in our next papers.

Figure 7 shows the IB of fiberboards containing LCNF. Comparing softwood and hardwood fiber, the IB values for hardwood fiberboard with and without LCNF were greater than those for softwood, though the mechanical entanglement among short fibers became weaker than for long fibers generally. Moreover, the IB tended to increase with increasing board density for the LCNF-mixed fiberboard. For all densities, the IB for LCNF-mixed fiberboard was higher than that for the control fiberboard. For the control fiberboard, neither LCNF nor adhesives were used. Because the thickness of the control fiberboard was recovered during conditioning, the IB value became very

Fig. 7 Specific internal bond strength $(\mathrm{IB} / \rho)$ of fiberboards containing LCNF a softwood fiber, b hardwood fiber. Vertical bars indicate standard deviations

small. On the other hand, the thickness of the LCNF-mixed fiberboard was not changed during conditioning, so the IB value was much higher. This is the reason that the nanosized fibril effectively trapped wood fibers. From these results, the IB value was improved by adding LCNF to fiberboard. Moreover, the reinforcement effect of LCNF was confirmed at all board densities.

Figures 8 and 9 show the degrees of thickness swelling (TS) and weight change (WC) in the wood fiber/LCNF composites with water absorption. As compared to softwood and hardwood fiberboards, the TS and WC for hardwood fiberboard with and without LCNF were lower than those for softwood fiberboards. The TS and WC values for fiberboards containing LCNF were lower than those for boards with fiber only. Nanosized fibrils formed at the fiber surface during the process of mixing LCNF with wood fiber resulted in close binding of the two components. As a result, water was not as easily able to enter the 

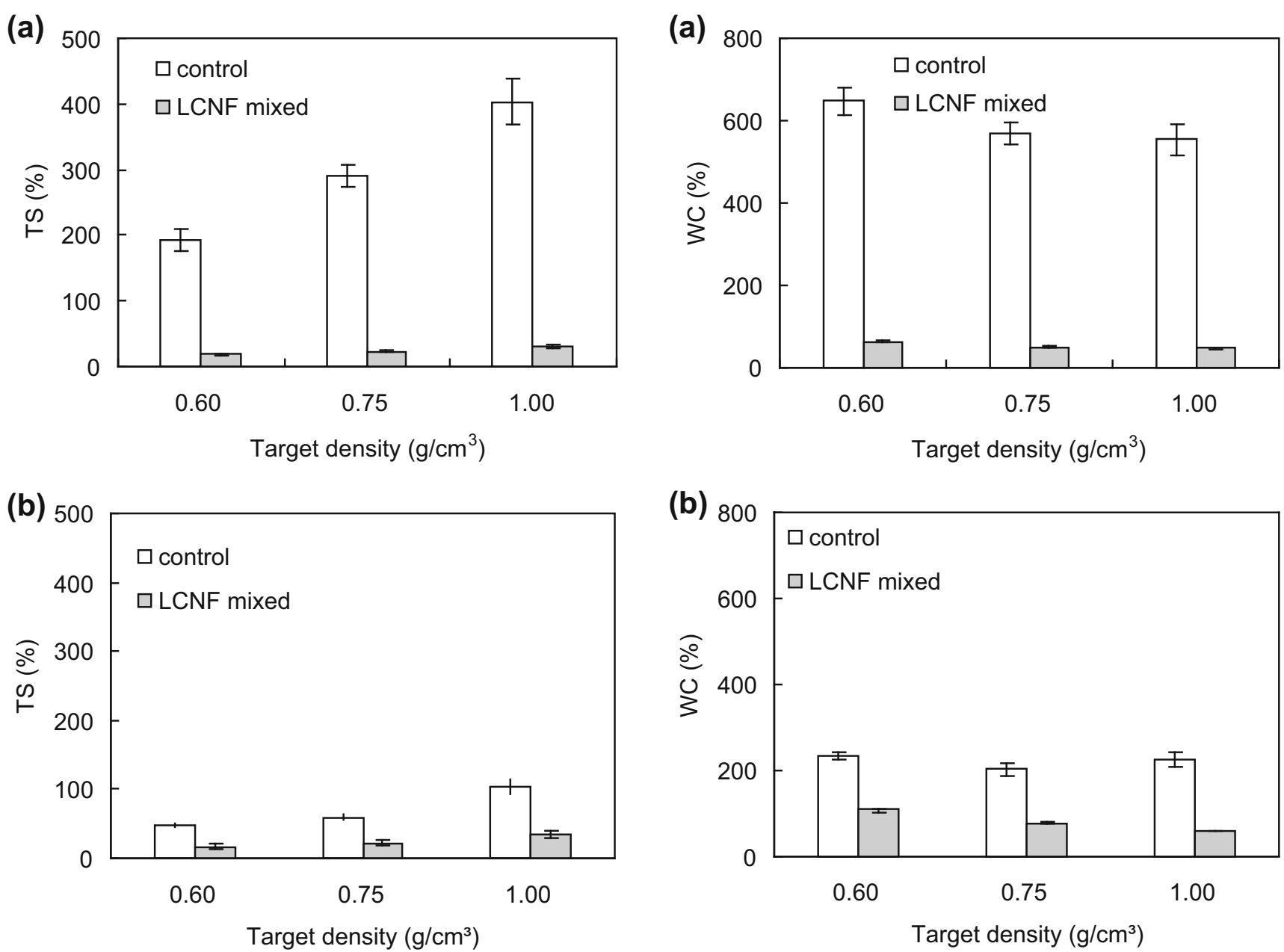

Fig. 8 Thickness swelling (TS) with the water adsorption test a softwood fiber, b hardwood fiber. Vertical bars indicate standard deviations

composite. Thus, incorporation of LCNF improved water resistance.

\section{Conclusions}

In this report, we discussed the reinforcement effect of LCNF in fiberboards, especially in relation to board density. Wet ball milling of both softwood and hardwood fibers resulted in the formation of nanostructured fibers with nanosized surface fibrils. A reliable and safe method presented in our previous report of manufacturing wood flour/LCNF boards could be applied to fiberboards. Physical and mechanical properties of the resulting fiberboards were significantly improved with the addition of LCNF, especially softwood fiberboards, due to close binding between LCNF and wood fibers. Moreover, the reinforcement effect of LCNF on fiberboards was confirmed at three different board densities. As the next steps, we would

Fig. 9 Weight change (WC) with the water adsorption test a softwood fiber, b hardwood fiber. Vertical bars indicate standard deviations

evaluate the reinforcement effect of LCNF on fiberboards in relation to LCNF size and LCNF/wood fiber composition.

\section{References}

1. Umemura K, Ueda T, Kawai S (2011) Characterization of woodbased molding with citric acid. J Wood Sci 58:38-45

2. Umemura K, Ueda T, Sasa SM, Kawai S (2012) Application of citric acid as natural adhesive for wood. J Appl Polym Sci 123:1991-1996

3. Umemura K, Ueda T, Kawai S (2012) Effects of molding temperature on physical properties of wood-based molding bonded with citric acid. For Prod J 62:63-68

4. Umemura K, Sugihara O, Kawai S (2013) Investigation of a new natural adhesive composed of citric acid and sucrose for particleboard. J Wood Sci 59:203-208

5. Ikeda K, Takatani M, Sakamoto K, Okamoto T (2008) Development of fully bio-based composite: wood/cellulose diacetate/ poly (lactic acid) composite. Holzforschung 62:154-156 
6. Takatani M, Ikeda K, Sakamoto K, Okamoto T (2008) Cellulose esters as compatibillizers in wood/poly (lactic acid) composite. J Wood Sci 54:54-61

7. Kondo T (2008) New aspects of cellulose nanofiber (in Japanese). Mokuzai Gakkaishi 54:107-115

8. Yano H (2007) New developments in bio-based materials (in Japanese). CMC Publishing Co. Ltd., Tokyo, pp 63-70

9. Lee S, Ohkita T (2003) Mechanical and thermal flow properties of wood flour biodegradable polymer composites. J Appl Polym Sci 90(7):1900-1905

10. Nakagaito AN, Yano H (2005) Novel highstrength biocomposites based on microfibrillated cellulose having nano-order-unit weblike network structure. Appl Phys A 80(1):155-159

11. Okubo K, Fujii T, Yamashita N (2005) Improvement of interfacial adhesion in bamboo polymer composite enhanced with microfibrillated cellulose. JSME Int J Ser A 48(4):199-204

12. Abe K, Iwamato S, Yano H (2007) Obtaining cellulose nanofibers with uniform width of $0.15 \mathrm{~nm}$ from wood. Biomacromolecules 8(10):3276-3278

13. Sehaqui H, Allais M, Zhou Q, Berglund LA (2011) Wood cellulose biocomposites with fibrous structure at micro-and nanoscale. Comp Sci Technol 71(3):382-387

14. Kojima Y, Minamino J, Isa A, Suzuki S, Ito H, Makise R, Okamoto M (2013) Binding effect of cellulose nanofibers in wood flour board. J Wood Sci 59:396-401

15. Kojima Y, Isa A, Kobori H, Suzuki S, Ito H, Makise R, Okamoto M (2014) Evaluation of binding effects in wood flour board containing lingo-cellulose nanofibers. Materials 7:6853-6864

16. Kojima $Y$, Ishino A, Kobori H, Suzuki S, Ito H, Makise R, Higuchi I, Okamoto M (2015) reinforcement of wood flour board containing lingo-cellulose nanofiber made from recycled wood. J Wood Sci 61:492-499

17. Halvarsson S, Edlund H, Norgren M (2009) Manufacture of nonresin wheat straw fiberboards. Ind Crops Prod 29(2-3):437-445

18. Wuzella G, Mahendran AR, Batge T, Jury S, Kandelbauer A (2011) Novel, binder-free fiber reinforced composites based on a renewable resource from the reed-like plant Typha sp. Ind Crops Prod 33(3):683-689
19. Baskaran M, Hashim R, Said N, Raffi SM, Balakrishnan K, Sudesh K, Sulaiman O, Arai T, Kosugi A, Mori Y, Sugimoto T, Sato M (2012) Properties of binderless particleboard from oil palm trunk with addition of polyhydroxyalkanoates. Comp Part B: Eng 43(3):1109-1116

20. Li X, Li Y, Zhong Z, Wang D, Ratto JA, Sheng K, Sun XS (2009) Mechanical and water soaking properties of medium density fiberboard with wood fiber and soybean protein adhesive. Bioresour Technol 100(14):3556-3562

21. Mancera C, El Mansouri NE, Pelach MA, Francesc F, Salvado J (2012) Feasibility of incorporating lignins in fiberboards made from agricultural waste. Waste Manage 32(10):1962-1967

22. Sun YC, Lin Z, Peng WX, Yuan TQ, Xu F, Wu YQ, Yang J, Wang YS, Sun RC (2014) Chemical changes of raw materials and manufactured binderless boards during hot pressing: lignin isolation and characterization. Bioresource 9(1):1055-1071

23. Takahashi H, Endoh K, Suzuki H (1972) Studies on handling process of wood fiber for dry processing of fiberboard. I. On particle size of ground fiber (in Japanese). Mokuzai Gakkaishi 18:9-13

24. Takahashi H, Endoh K, Suzuki H (1972) Studies on handling process of wood fiber for dry processing of fiberboard. II. Particle size distribution of ground wood fiber (in Japanese). Mokuzai Gakkaishi 18:15-19

25. Takahashi H, Endoh H, Ohsawa K, Moriyama M, Endoh K (1974) Effects of characteristics of fiber ground by refiner on physical properties of fiberboard. I. Shape of a fiber and mechanical strength of fiberboard (in Japanese). Mokuzai Gakkaishi 20:430-434

26. JIS A 5905 (2014) JIS standard specification for fiberboards. Japanese Standards Association, Tokyo

27. Ito H, Kumari R, Takatani M, Uchiyama M, Okamto T, Hattori H, Fujiyoshi I (2008) Viscoelastic evaluation of effects of fiber size and composition on cellulose-polypropylene composite of high filler content. Polym Eng Sci 48:415-423 